\title{
Study of Great Saphenous Vein and its Tributaries at the Saphenofemoral Junction and its Variations
}

\author{
Jinu T. Eldho' ${ }^{1}$ Ushadevi K.B. ${ }^{2}$ \\ ${ }^{1}$ Department of Anatomy, Dr. Somervell Memorial CSI Medical College, Karakonam, Kerala, India. \\ ${ }^{2}$ Department of Anatomy, Government Medial College, Kozhikode, Kerala, India.
}

\section{ABSTRACT}

\section{BACKGROUND}

Great saphenous vein is the largest and thickest walled superficial vein of the lower limb. It ascends on the medial border of the tibia to the posteromedial surface of the knee and inclines anteriorly over the thigh to enter the femoral vein through the saphenous opening. The centre of the opening is $2.5-3.5 \mathrm{cms}$ inferolateral to the pubic tubercle. Among various venous anatomical variations in lower limbs, most important and significant variations occur at the saphenofemoral junction. The study was focussed on the tributaries of great saphenous vein at the saphenofemoral junction and its variations.

\section{METHODS}

The study was conducted on 80 surgical cases who underwent Trendelenburg surgery and in 30 cadavers from the Department of Anatomy. The specimens were dissected according to the steps in Cunningham's Manual of Practical Anatomy. Saphenofemoral junction was studied in detail with emphasis on number of tributaries, variation in the drainage pattern of tributaries and duplication of great saphenous vein. Data obtained were consolidated, statistically evaluated using SPSS Version 16 and results obtained were represented using charts and tables.

\section{RESULTS}

According to our study, varicosity of the great saphenous vein was more prevalent in the age group 41-50 years (25\%) and there was a male predominance. The number of tributaries at the SFJ varied from 1-7 with highest frequency of three tributaries in $57 \%$ of cases. Distance of saphenofemoral junction from pubic tubercle varied from 2.60 to $4.20 \mathrm{cms}$. Duplication of great saphenous vein was noted in $16.7 \%$ of cadavers. In $66.7 \%$ of cases draining pattern was normal.

\section{CONCLUSIONS}

In the present study, we found a significant variation of tributaries at the saphenofemoral junction. Although knowledge in venous anatomy and variations may not be necessary in conservative approach, interventional treatment modalities may necessitate expertise. Hence if important anatomical variations are not recognised, surgical or less invasive procedures might result in incomplete saphenofemoral junction surgery. Consequently, the knowledge and identification of anatomical variations play an important role in increasing the success and efficacy of surgical treatments and in decreasing recurrence rates of varicose veins.
Corresponding Author: Dr. Ushadevi K. B., Department of Anatomy, Government Medial College, Kozhikode, Kerala, India.

E-mail: ushakbdevi1@gmail.com

DOI: $10.14260 / j e m d s / 2019 / 761$

Financial or Other Competing Interests: None.

How to Cite This Article:

Eldho JT, Ushadevi KB. Study of great saphenous vein and its tributaries at the saphenofemoral junction and its variations. J. Evolution Med. Dent. Sci. 2019;8(47):3521-3525, $10.14260 /$ jemds $/ 2019 / 761$

Submission 26-07-2019, Peer Review 02-11-2019, Acceptance 08-11-2019, Published 25-11-2019.

\section{KEY WORDS}

Great Saphenous Vein, Saphenofemoral Junction, Varicose Veins 


\section{BACKGROUND}

Great saphenous vein is the largest and thickest superficial vein of the lower limb. It begins on the medial side of the dorsum of the foot and runs upwards and backwards anterior to the medial malleolus and then on the medial surface of the distal third of the tibia. It then ascends on the medial border of the tibia to the posteromedial surface of the knee and inclines anteriorly over the thigh to enter the femoral vein through the saphenous opening. [1] The centre of the opening is often said to be $2.5-3.5 \mathrm{~cm}$ inferolateral to the pubic tubercle. However, the saphenous opening varies greatly in size and disposition so that this centre is not a reliable surface marking for the saphenofemoral junction. ${ }^{2]}$

Saphenofemoral junction is a sophisticated structure comprising of the arch of great saphenous vein, terminal and pre- terminal valves plus a number of tributaries.[3] In the thigh near the saphenofemoral junction, the great saphenous vein receives posteromedial and anterolateral veins. The deep external pudendal vein, superficial epigastric vein, superficial circumflex iliac vein and superficial external pudendal vein enter the great saphenous vein at the fossa ovalis.[4]

Ligation of saphenofemoral junction in flush with the femoral vein after ligating and dividing the known and unknown tributaries (Trendelenburg's procedure) is a timetested method of treating saphenofemoral incompetence in primary varicose veins. Among various venous anatomical variations in lower limbs, most important and significant variations occur at the saphenofemoral junction. The junction is identified $2.5 \mathrm{~cm}$ inferior and $4 \mathrm{~cm}$ lateral to pubic tubercle. An incision made at this point however fails to accurately reach the saphenofemoral junction frequently, thereby chance of injury to femoral vessels and failure in flush ligation results in recurrence.[5]

A complete knowledge about anatomical variation in SFJ and variations in tributaries of great saphenous vein is important during surgery ensuring that the junction is safely managed in the least aggressive and most effective way. The major causes of recurrences of varicose veins were identification of GSV stump with non-ligated tributaries, a completely intact SFJ, nonidentification of bifid system and presence of non-ligated junctional tributaries.[6]

We wanted to assess the tributaries of great saphenous vein at the saphenofemoral junction and the variations of tributaries at the saphenofemoral junction.

\section{METHODS}

This is a descriptive study conducted in the Department of General Surgery, and the Department of Anatomy, Govt. Medical College, Thiruvananthapuram over a period of two years after approval by the Human Ethics Committee, Govt. Medical College, Thiruvananthapuram.

\section{Sampling Method}

Census type of sampling

\section{Sample Size}

Sample size was calculated by the formula $n=z \propto p q / d 2$ $\mathrm{z} \propto=3.84, \mathrm{p}=78.3$ (according to the study by Carolina Vas et al) $\mathrm{q}=100-\mathrm{p}, \mathrm{d}=10 \%$ of $\mathrm{p}$

$$
\mathrm{n}=3.84 \times 78.3 \times 21.7 / 7.82^{2}=108
$$

Sample size was 110 , out of which 80 samples were taken from Department of Surgery and 30 samples were taken from cadavers of Dept. of Anatomy.

\section{Statistical Analysis}

Data obtained were consolidated, statistically evaluated using SPSS software version 16 and results obtained were represented using charts and tables.

\section{Study Sample}

The study was undertaken on 80 patients undergoing Trendelenburg surgery in the Dept. of Surgery, Govt. Medical College, Thiruvananthapuram and 30 specimens were obtained from the cadavers of Dept. of Anatomy, Govt. Medical College, and Thiruvananthapuram.

\section{Inclusion Criteria}

1. Patients undergoing Trendelenburg surgery in the department of General Surgery, Govt. Medical College, Thiruvananthapuram.

2. Cadavers from Department of Anatomy, Govt. Medical College, Thiruvananthapuram.

\section{Exclusion Criteria}

1. Patients with previous history of surgical procedures at groin.

2. Patients undergoing surgery for recurrent varicose veins.

3. Cadavers with traumatic lesion, pathological lesion and surgical intervention at the groin.

\section{Study Procedure}

A skin crease incision was made in the groin below and parallel to inguinal ligament at the site of saphenofemoral junction (below and lateral to pubic tubercle). The incision was carried down through the subcutaneous tissues so that great saphenous vein was identified. The first five centimeters of great saphenous vein were explored and thoroughly studied. The tributaries at the saphenofemoral junction was ligated and Trendelenburg surgery was performed.

\section{RESULTS}

\section{Age Distribution}

Out of 80 cases, $23.8 \%$ belonged to the age group 40 and less, $25 \%$ belonged to the age group $41-50$ years, $22.5 \%$ belonged to $51-60$ years, $20 \%$ belonged to the age group $61-70$ years and $8.8 \%$ belonged to the age group 71 and above years of age. Highest frequency belonged to the age group 41-50 years of age.

\section{Gender Distribution}

Out of the 110 samples, $62.73 \%$ were obtained from the males and $37.27 \%$ were obtained from the females. 


\section{Number of Tributaries}

The number of tributaries draining at the saphenofemoral junction were noted in cadavers as well as patients undergoing Trendelenburg surgery. In both samples, the maximum number of tributaries identified was seven and minimum number was one. In $57 \%$ of surgical patients, three junctional tributaries were identified.

\begin{tabular}{|c|c|c|}
\hline Number & Frequency & Percent \\
\hline 1 & 2 & 6.7 \\
\hline 2 & 5 & 16.7 \\
\hline 3 & 16 & 53.3 \\
\hline 4 & 2 & 6.7 \\
\hline 5 & 3 & 10.0 \\
\hline 6 & 1 & 3.3 \\
\hline 7 & 1 & 3.3 \\
\hline Total & $\mathbf{3 0}$ & $\mathbf{1 0 0 . 0}$ \\
\hline \multicolumn{2}{|c|}{ Table 1. Number of Tributaries in Cadavers } \\
\hline
\end{tabular}

\begin{tabular}{|c|c|c|}
\hline Pattern of Drainage & Frequency & $\%$ \\
\hline Draining directly into SFJ & 55 & 68.8 \\
\hline $\begin{array}{l}\text { Superficial epigastric \& superficial circumflex iliac vein } \\
\text { forming a common trunk to drain into SFJ }\end{array}$ & 9 & 11.3 \\
\hline $\begin{array}{l}\text { Anterolateral vein \& superficial circumflex iliac vein forming a } \\
\text { common trunk to drain into SFJ }\end{array}$ & 5 & 6.3 \\
\hline $\begin{array}{l}\text { Superficial epigastric \& superficial external pudendal vein } \\
\text { forming a common trunk to drain into SFJ }\end{array}$ & 6 & 7.5 \\
\hline $\begin{array}{l}\text { Superficial circumflex iliac vein \& superficial external } \\
\text { pudendal vein forming a common trunk to drain into SFJ }\end{array}$ & 3 & 3.8 \\
\hline $\begin{array}{l}\text { Superficial epigastric, superficial circumflex iliac \& } \\
\text { anterolateral vein forming a common trunk to drain into SFJ }\end{array}$ & 2 & 2.5 \\
\hline Total & 80 & 100.0 \\
\hline
\end{tabular}

\section{DISCUSSION}

Variations and abnormalities are more frequently reported in veins than arteries. The variations are more common in the upper segment of the great saphenous vein in its tributaries where it ends into the femoral vein. ${ }^{[4]}$ Embryological source of this variation may be explained as an abnormal deviation from the normal process of embryonic development of vascular process. ${ }^{[7]}$

\section{Age Distribution}

In the study done by Thrisuli. P. B et al, prevalence of varicose veins was more among the age group 40-50 years (38.3\%). ${ }^{[5]}$ Kshitij et al found that $66 \%$ of the study group belonged to less than 50 years of age and $34 \%$ belonged to the age group above 50 years. ${ }^{[6]}$ Hemmatti et al in their study showed that the mean age of the patients with varicose vein was 45 years and the range was 17 to 81 years of age.[8] In our study, highest frequency (53\%) belonged to the age group 41-50 years of age which was in correspondence with most of the previous studies.

\section{Gender Distribution}

In the study done by Thrisuli et al, prevalence was more common in males with $93.3 \%$ which may be due to more male patients admitted. Hence the prevalence in hospital admitted cases is more in male population. [5] Kshitij et al found that the male: female ratio was $57: 1.2 .{ }^{[6]}$ In the study done by Hemmatti et al, out of 228 patients, 146 (64\%) were male and 82 (36\%) were female.[8] Carolina Vaz et al observed that the prevalence of variations at saphenofemoral junction was more in women (75\%) than in males.[9] In our study $62.73 \%$ of the samples were obtained from the males and $37.27 \%$ were obtained from the females which was consistent with the study done by Hemmatti et al. There is no consistency in the literatures as to gender differences in prevalence of varicose veins.

\section{Number of Tributaries at the Saphenofemoral Junction}

In the study conducted by Kshitij et al, the number of tributaries at the saphenofemoral junction varied from 2 (2\%) to 6 (2\%). Most frequent number of tributaries was 3 in $42 \%$ cases.[6] Pourhasssan et al identified 3 junctional tributaries in $57.4 \%$ cases.[10] The number of tributaries as noted by H. G. Kluess et al varied from 2 to 8[11] $^{[1}$ and that of Donelly $M$ varied from 1 to 10.[12] In the present study, number of tributaries varied from one to seven. The mean was found to be 3.20 with a standard deviation of 1.324 . This finding corresponds to most of the findings in the previous studies. The variation in the number of tributaries may be either due to racial differences or due to different ways of counting the tributaries ie, some surgeons tend to count all the tributaries on a single trunk as one at the saphenofemoral junction.

\section{Right and Left Side Variation at the Saphenofemoral Junction}

In $48.7 \%$ of surgical patients of our study, variation of the saphenofemoral junction was detected on the right side and in $51.3 \%$ of the cases, it was detected on the left side. In the study done by Thrisuli et al variation at the saphenofemoral junction was reported on right side in 37 cases out of 60 cases studied and on left side in 23 cases.[5] In the study done by Carolina Vaz et al 189 consecutive operative procedures were performed at the saphenofemoral junction: 103 cases on right side and 86 cases on left side.[9] There were not much studies done on sidewise variation of the saphenofemoral junction to compare our data.

\section{Distance of Saphenofemoral Junction from the Pubic Tubercle}

In our study, distance of saphenofemoral junction from the pubic tubercle was measured. It varied from $2.60 \mathrm{~cm}$ to 4.20 $\mathrm{cm}$ on the right side and $2.70 \mathrm{~cm}$ to $3.90 \mathrm{~cm}$ on the left side. Our finding was in accordance with most of the previous studies quoted below. Thrisuli et al reported the ultrasound guided location of saphenofemoral junction was at mean distance of $3.641 \mathrm{~cm}$ below and lateral to pubic tubercle.[5] Study done by Mirjalili stated that the centre of saphenofemoral junction was $2.4+/-0.6 \mathrm{~cm}$ below and lateral to pubic tubercle (range: $2.5-4.0)^{[13]}$ while the distance reported by Kshitij et al was $3.77+/-0.61 \mathrm{~cm} .{ }^{[6]}$

\section{Duplication of Great Saphenous Vein}

\begin{tabular}{|c|c|}
\hline Present Study & $\mathbf{1 6 . 7} \%$ of Cadavers \& 12.5 \% of Surgical Cases \\
\hline Glasser & $3 \%$ of anatomical dissections \\
\hline Allen \& colleagues & $18 \%$ of anatomical dissections \\
\hline Capuano and colleagues (1975) & $12.5 \%$ ) of cases \\
\hline Burnand and colleagues & $16 \%$ cases of vascular surgery \\
\hline Dhiraj M Shah & $35 \%$ of cases \\
\hline Chandler et al & $35 \%$ of cases \\
\hline Mark H Meissner & $8 \%$ of cases \\
\hline Donnelly M et al & $18.1 \%$ of study population \\
\hline \multicolumn{2}{|c|}{ Table 3. Duplication of Great Saphenous Vein } \\
\hline
\end{tabular}


The earliest study was done by Glasser in 1942. He performed anatomical dissection on 100 limbs and found duplicated saphenous vein in 3 limbs.[14] Allen \& colleagues found duplication of GSV in $18 \%$ of anatomical dissections, ${ }^{[15]}$ Capuano and colleagues in $12.5 \%$ of cases, ${ }^{[16]}$ Burnand et al in $16 \%$ cases of vascular surgery ${ }^{[17]}$ and Donelly $\mathrm{M}$ et al in $18 \%$ of study population.[12]

\section{Pattern of Drainage of Tributaries at the Saphenofemoral Junction}

In $66.7 \%$ of cases in our study, draining pattern was normal while in other cases, the tributaries joined to form a common trunk. According to the study done by K Udhaya et al, out of 70 specimens $(30 \%)$ showed a normal pattern of superficial circumflex iliac vein, superficial epigastric and superficial external pudendal vein draining directly at saphenofemoral junction. The posteromedian vein drained along with superficial external pudendal vein in $5.7 \%$ of cases. The posteromedian vein drained directly into great saphenous vein at fossa ovalis in $7.14 \%$ cases. In $24.2 \%$ specimens, anterolateral vein drained with superficial circumflex iliac vein and superficial epigastric vein. In $7.14 \%$ cases anterolateral vein drained directly at saphenofemoral junction, in $2.85 \%$ it drained along with superficial circumflex iliac vein. ${ }^{[4]}$ M.H Chung et al reported that the postero median vein joined to form a common trunk with superficial external pudendal vein at an incidence of $14.1 \%$ or with superficial epigastric vein and superficial external pudendal vein in a $3.6 \%$ incidence and directly in $82.3 \%$ cases. The anterolateral vein drained directly in $38.6 \%$ incidence. Superficial epigastric and superficial external pudendal vein joined to form a common trunk in $12.5 \%$ cases, superficial epigastric and superficial circumflex iliac vein in $0.8 \%$, superficial epigastric and anterolateral vein in $9.2 \%$ cases. The superficial circumflex iliac vein drained directly in $56.6 \%$ cases or formed a common trunk by joining with superficial epigastric vein $(0.8 \%)$. The superficial external pudendal vein and superficial epigastric vein drained directly at the saphenofemoral junction in $61.95 \%$ and $45 \%$ incidence.[18]

\section{CONCLUSIONS}

The knowledge and identification of anatomical variations of saphenofemoral junction play an important role in increasing the success and efficacy of surgical treatments in varicose veins and in decreasing recurrence rates. Pre-operative knowledge of each individual's saphenous vein is important for several reasons. It permits accurate placement of skin incisions and minimises a major source of frustration during the operative procedure. Recurrent varicose veins after surgery is a common problem which has different causes such as inadequate assessment for the presence of DVT, anatomical variation at saphenofemoral junction, postoperative neovascularisation etc. Failure to ligate the major tributary veins would not be surprising considering the anatomical complexity and has been attributed to the efforts of less experienced surgeons. A double saphenous vein can be an explanation for recurrent incompetence of the great saphenous vein due to a persistently duplicated trunk.

There have been revolutionary developments in the diagnosis and treatment of chronic venous insufficiency in recent years. The treatment options of varicose veins include conservative approach, sclerotherapy, ultrasound guided sclerotherapy and junctional ligation with or without stripping. Although expertise in venous anatomy and variations may not be necessary in conservative approach, interventional treatment modalities may necessitate expertise. Hence if important anatomical variations are not recognised, surgical or less invasive procedures might result in incomplete saphenofemoral junction surgery.

\section{REFERENCES}

[1] Romanes GJ. Cunnigham's Manual of Practical Anatomy. Upper limb and lower limb. Vol. 1. 15 th edn. New York: Oxford University Press 2003.

[2] Standring S. Gray's Anatomy: The anatomical basis of clinical practice. $40^{\text {th }}$ edn. Churchill Livingstone/ Elsevier 2008.

[3] Dickson R, Hill G, Thomson IA, et al. The valves and tributary veins of the saphenofemoral junction: ultrasound findings in normal limbs. Veins and Lymphatics 2013;2(18):63-7.

[4] Udhaya K, Rajendran M, Sridhar J. Variations in the tributaries of Great saphenous vein at the saphenofemoral junction and its clinical implication. National Journal of Basic Medical Sciences 2011;1(4):190-3.

[5] Thrishuli PB, Nithyananda HA, Reddy S. Study of the surgical anatomy of the sapheno-femoral junction. International Journal of Scientific Research 2015;4(7):291-7.

[6] Manerikar K, Bawa APS, Pithwa AK, et al. Risk factors and Sapheno-femoral junction in Varicose Veins. Indian Journal of Vascular and Endovascular Surgery 2015;2(4):134-8.

[7] Yerolavi SN. Variations in the course and termination of great saphenous vein: a case report. Journal of Evolution of Medicine and Dental Sciences 2015;4(48):8420-4

[8] Hemmati H, Baghi I, Zadeh TK, et al. Anatomical variations of sapheno-femoral junction in patients with varicose veins. Acta Medica Iranica 2012;50(8):552-5.

[9] Vaz C, Machado R, Rodrigues G, et al. Anatomical variation of the Sapheno-femoral junction - a prospective study in a population with primary superficial venous insufficiency. Angiologia e Cirurgia Vascular 2013;9(1):1-5.

[10] Pourhassan S, Zarras K, Mackrodt HG, et al. Recurrent varicose veins. Surgical procedure-results. Zentralab Chir 2001;126(7):522-5.

[11] Kluess HG, Rabe E, Gallenkemper G, et al. The anatomy of the saheno-femoral junction - a vascular network with therapeutic implications. Phlebology 1995;1:45-7.

[12] Donnelly M, Tiernery S, Feeley TM. Anatomical variation at the Sapheno-femoral junction, $\mathrm{Br} J$ Surg 2005;92(3):322-5.

[13] Mirjalili SA, Muirhead JC, Stringer MD. Redefining the surface anatomy of the saphenofemoral junction in vivo. Clinical Anatomy 2014;27(6):915-9. 
[14] Glasser ST. Variations of the tributaries of the saphena magna at the sahenofemoral junction: abstract of demonstration. Anatomical Record 1942;82:289-95.

[15] Gaylis H. The duplicated saphenous veins in femoropopliteal bypass grafting. Surgery 1970;67(2):277-8.

[16] Capuano G, Biannic F, Biannic G, et al. Anatomical study of the arch of the internal saphenous vein (saphena magna) in man. Bull Assoc Anat 1975;59(147):807-17.
[17] Burnand KG, Senapati A, Thomas ML, et al. A comparison of preoperative long saphenous phlebography with operative dissection in assessing the suitability of long saphenous vein for use as a bypass graft. Ann R Coll Surg Engl 1985;67(3):183-6.

[18] Chun MH, Han SH, Chung JW, et al. Anatomical observations on draining patterns of saphenous tributaries in Korean adults. Journal of Korean Medical Science 1992;7(1):25-33. 